\title{
Regional Development Agencies in Portugal: Recent Development and Future Challenges
}

\section{Stephen Syrett \& Carlos Nunes Silva}

To cite this article: Stephen Syrett \& Carlos Nunes Silva (2001) Regional Development Agencies in Portugal: Recent Development and Future Challenges, Regional Studies, 35:2, 174-180, DOI: 10.1080/00343400120033160

To link to this article: https://doi.org/10.1080/00343400120033160

曲 Published online: 18 Aug 2010.

Submit your article to this journal

Џlll Article views: 176

Citing articles: 11 View citing articles 주 


\section{Regional Development Agencies in Portugal: Recent Development and Future Challenges}

\author{
STEPHEN SYRETT* and \\ CARLOS NUNES SILVA† \\ *Centre for Enterprise and Economic Development Research, \\ Middlesex University, Queensway, Enfield EN3 4SF, UK. \\ Email:s.syrett@mdx.ac.uk \\ †Centro de Estudos Geográficos, Faculdade de Letras da \\ Universidade de Lisboa, Lisboa 1600-214, Portugal. \\ Email:carlos.silva@fc.ul.pt
}

This article considers the result of a recently completed programme to create Regional Development Agencies (RDAs) within Portugal. The first part of the article examines the forces leading to the creation of RDAs in Portugal and the particularities of the process employed. The second part turns to consider the considerable challenges that these fledgling RDAs now face if they are to develop a strategic role promoting regional economic development within Portugal.

Regional Development Agencies Portugal

Governance Partnership Regional development

\section{Introduction}

In the second half of the 1990s, a process to create a set of Regional Development Agencies (RD As) began in Portugal. The government sponsored IQADE (Implementation and Qualification of Development Agencies) programme formally came to an end in July 2000 with the result that 16 R D As now operate across the majority of mainland Portugal and one on the island of Madeira. The process creating these RDAs is interesting in a number of respects. First, national government policy attempted to stimulate a bottomup approach, with agencies emerging from particular regional contexts, rather than being imposed rigidly from the centre. Second, the fortunes of the nascent RDAs have been closely related to the fluctuating political agenda concerning regional development and attempts to develop new forms of sub-national governance. The result is a suite of RDAs characterized by significant differences in their organization and capacities, and a national policy agenda which appears somewhat uncertain as to their future role. Given this context, it appears timely to briefly review the RDA creation process in Portugal and consider the extent to which these fledgling agencies are likely to play a significant role in future regional governance within Portugal.

\section{Changing forms of regional governance}

Considerable attention has focused recently upon changes in the nature of local and regional governance and the significance of such changes to processes of socio-economic transition and forms of sub-national governance (e.g. JESSOP, 1994; LlOYD and MEEGAN, 1996; TEWDWR-JONES and MCNeILl, 2000). Emerging from such changes are new institutional arrangements which reflect a shift from government to governance, the increased importance of the neo-liberal agenda and the importance of specific local and regional contexts (e.g. NEWMAN, 2000; KEARNS and PADDISON, 2000). The creation of RD As in Portugal illustrates how such changes in the nature and institutions of sub-national governance are currently being played out within a particular national context in the European Union's southern periphery.

In the latter part of the 1990s, the creation of a national set of RDAs became increasingly prominent within the Portuguese regional policy agenda for a number of reasons. First, the profound period of economic growth and restructuring which Portugal experienced from the mid-1980s created a number of pressures relating to processes of urban and rural development, economic modernization and changing lifestyles and cultural values. The resulting need to improve provision of infrastructures and public services and promote more rapid economic modernization led to increased recognition of the importance of a more coordinated regional level response. Furthermore, the necessity of reinforcing the competitive basis of regions within an economy becoming increasingly globalized, also pointed to the importance of stronger regional governance structures.

Second, in the face of such rapid economic change, existing government structures often proved inadequate. The only existing regional structures, the CCRs (Regional Planning Commission) have limited abilities to pursue autonomous regional policies. The CCRs form part of the central state administration, which controls the scope of their activities, and they lack any direct democratic accountability to the regional population. Below the regional level, the rapid growth and fragmentation of local level institutions provided further impetus for a degree of regional co-ordination.

Third, on coming to power in 1995, the new PS (Socialist Party) government's agenda was to reinforce the regional level of political administration and promote greater partnership between the state and civil society (INCM, 1999; MEPAT, 1999). This approach built on a similar vision of partnership working as outlined in Portugal's Second Community Support Framework (CSF-II, 1994-99), which indeed provided support for the creation of development agencies. In this respect, national government policy both by the PS and the previous PSD (Social Democratic Party) administration was strongly influenced by the policy directions of the EC towards promoting a 'Europe of the Regions'. The centrepiece of the PS administration's decentralization strategy was the proposals for the creation of elected regional administrations (COR KILL, 
1999; Silva, 2001 (forthcoming)). The rejection of these proposals in a national referendum in 1998 forced the government to look towards new ways of taking forward its decentralization strategy and gave added momentum to the process of creating RDAs which by then was already underway.

\section{The creation of Regional Development Agencies in Portugal: the IQADE programme}

Against this background the process of creating a national network of certificated RDAs formally began in 1997 under the auspices of the IQADE programme (IQADE, 1997). ${ }^{1}$ In a desire to promote new forms of partnership working, the decision was to pursue a bottom-up model aimed at promoting agencies strongly rooted within the regions, rather than imposing RD As from the centre. The process for taking this forward was contracted to an existing regional development agency, the CDR Cooperação e Desenvolvimento Regional, S.A., which had been operating successfully in the Setúbal region since 1992.

The IQADE programme aimed to stimulate and support the creation and/or consolidation of development structures at the local or regional level through the supply of technical assistance (PPDR, 1998). From the outset RD As were conceived as being independent, inter-institutional organizations with a technical character, which would be self-financing and act to promote regional development. In pursuing a bottom-up process, there was an explicit recognition that RDAs should be able to adopt different organizational forms appropriate to local circumstances. The process required interested parties to organize regionally based partnerships, develop a plan of activities and put forward an application to become a certificated agency in accordance with the programme requirements.

IQADE encouraged both public and private bodies to constitute RDAs. RDAs could be either entirely new, an upgrading of existing structures, or created via the coming together of existing local development agencies into a form which gave them a regional scale of operation. The process also received support from the European Association of Development Agencies, EURADA, which provided a network for the transfer of know-how from existing European development agencies. Despite the flexibility in the forms of RDAs, they had to meet a number of basic criteria: (1) formation as public-private partnerships; (2) coverage of a population of 300,000 inhabitants and at least a NUT-III unit; (3) all profits to be reinvested if constituted as a private or limited company; and (4) presentation of a business plan demonstrating that the agency was self-sustaining.

An intensive series of regional meetings to disseminate information on the programme generated 44 applications. On the basis of modified criteria ${ }^{2} 22$ applications went forward for further consideration and, by July 1999, 17 had been officially constituted and registered. Legislation published in March 1999 clarified the nature and functions of the new RDAs, especially in relation to the central state. ${ }^{3}$ The RDAs are not part of the public sector and have total autonomy from the state. In all cases the agencies are in effect a 'partnership of partnerships' with many of the participating partnerships of a public-private nature. They can assume a variety of legal forms (limited companies, associations, foundations, co-operatives, civil or commercial societies, etc.) and partners can include public, private, voluntary or community sector organizations. ${ }^{4}$ As non-public bodies, RDAs can receive state support via a contract with the government. This contract permits RDAs to apply to supply technical and financial assistance in relation to specific regional development programmes in which a role for the RDAs is recognized (Ministério de Planeamento, 2000a). As the RDAs will benefit from state support via these contracts, a mechanism for a degree of public control via CCR supervision of their technical and financial assistance roles has been put in place.

RD As are intended to provide an institutional forum for bringing together all agents and sectors of a region in order to construct a regional consensus which goes beyond the narrow interests of existing organizations and will provide the basis for a regional strategy. The legislation defining the objectives of the RDAs provides them with a remit to promote economic, social and cultural objectives for a designated part of the national territory within the context of approved national level policies and strategies. Under the legislation the principal functions of the RDA are to promote initiatives with a regional impact, to promote the region externally and create information networks in association with other regional actors. Activities which are specified principally relate to economic development and include: the collection and supply of information; attraction of external investment; incentives for the creation of small firms; promotion of infrastructures for regional development; promotion of regional products; preparation and negotiation of regional plans and programmes; as well as the promotion of conferences and debates over regional questions. The RDAs are also to contribute to the definition of national regional development policies through their participation in various consultative bodies.

At the end of the first phase of the IQADE process, it was decided to extend support to the nascent RDAs in order to build upon the investments already made and fulfil rising expectations. The principal objective of the resulting second phase of IQADE (IQADEII) was to consolidate the technical and organizational aspects of the RDAs and to support their integration into the national and European context (PROMOÇÃO Do Potential de Desenvolvimento Regional (PPDR), 2000). The focus here was centred on the staff of the new RDAs and encouraging the develop- 
Table 1. Regional Development Agencies in Portugal, 2000

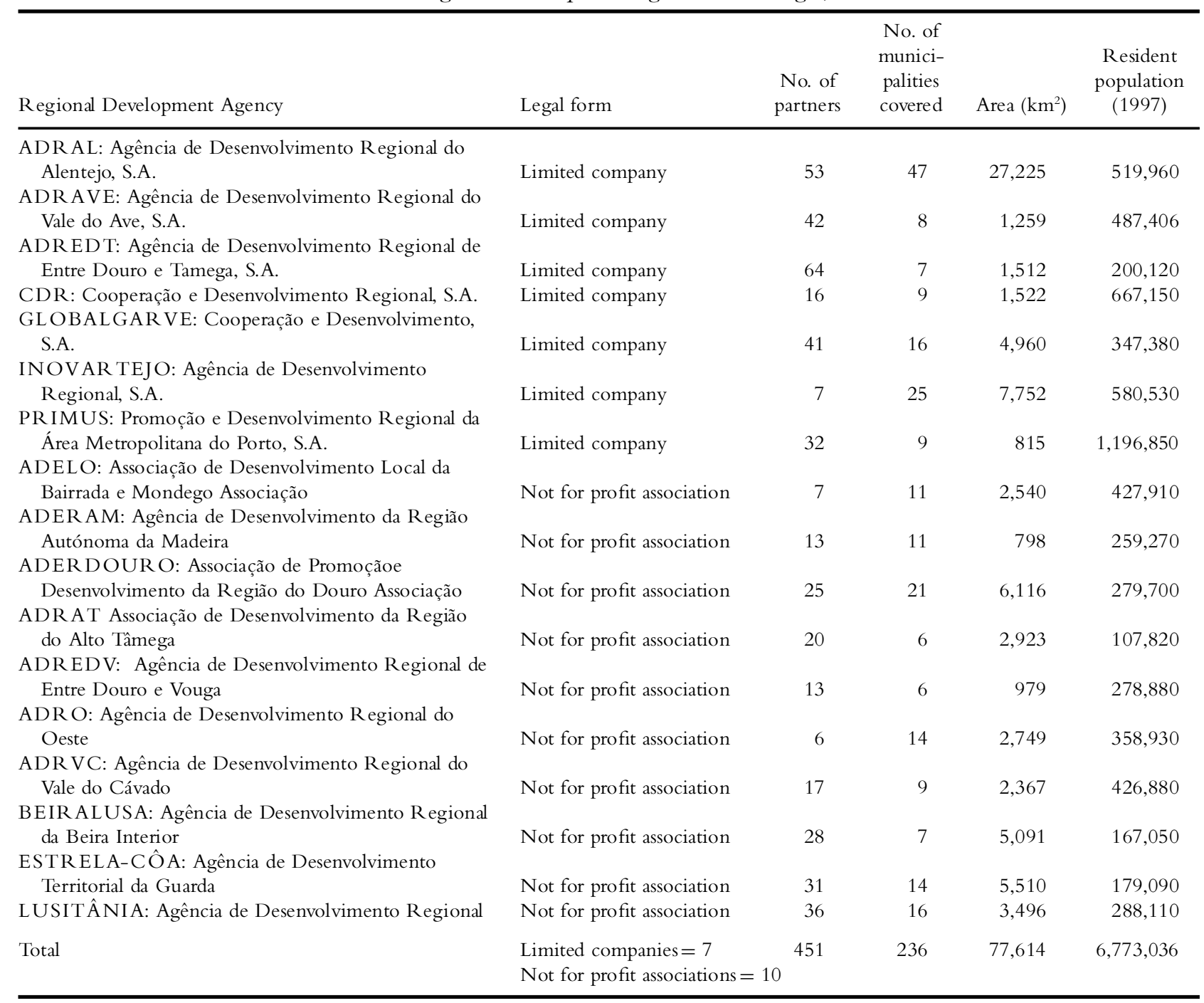

Source: Developed from PPDR/IQADE-II, 2000; DGAL, 1999.

ment of their technical skills and knowledge of the work of other RD As nationally and internationally. In particular there was a strong focus on developing contact with RD As operating elsewhere in Europe within similar economic contexts.

Although the legislation permits RDAs to adopt diverse legal forms, in reality the RDAs have chosen two forms: limited companies (41\%); and not-for-profit associations (59\%) (see Table 1). Nationally the RD As cover $77 \%$ of municipalities, $85 \%$ of the land area and $68 \%$ of the resident population. The most notable area not covered by a RDA is the Lisbon Metropolitan area. The geographical scale of the RDAs varies between the smallest, which cover only six municipalities (ADREDV e ADRAT), and the largest which covers 47 (ADR AL). The number of partners which make up the RDAs again varies considerably between those with only a restricted number of members (e.g. ADRO with only six), and others with a wide ranging membership (e.g. ADREDT with 64). There is con- siderable diversity in the partners which include municipalities, associations of municipalities, CCRs, business associations, financial institutions, private firms, further and higher education establishments, cultural associations, tourism bodies, trades unions, co-operatives, sectoral and locally based development associations and charitable organizations amongst others. In total, 451 institutions are involved in the agencies which provides some indication of the degree of mobilization of civil society and local administration achieved by the IQADE process.

The RD As are characterized by a very small technically qualified staff in relation to the objectives for which they were created. The current level of technical staff employed by the agencies on average consists of two to three higher level technical staff within an overall total of five to six..$^{5}$ This limited in-house technical staff is supplemented by the use of external consultants. There is a high proportion of recently qualified young staff reflecting the lack of an existing 
pool of experienced staff operating within regional development activity. The limitations of the staff base necessarily restricts the scope of the RDAs current activities. For most RDAs, business plans for their first year of operation prioritize the need to enlarge the partnership and conclude the implementation of IQADE-II. Activities currently being implemented or under development exhibit considerable diversity and commonly include the collection of regional economic information, development of sectoral strategic plans, valorization of indigenous resources, territorial marketing, integrated tourism initiatives, small firm technical assistance, environmental protection and energy conservation and more general promotion of regional events, conferences and workshops.

\section{Challenges for the future of the $R D A s$}

Portuguese RDAs reflect an interesting shift towards new forms of spatial governance characterized by interinstitutional partnerships. Given the prevailing political tradition of administrative centralization which has militated against cross-sectoral and multi-level partnerships (SYRETT, 1997), the creation of the RDAs provide further evidence of a shift towards new forms of governance within Portugal (MOREIRA, 1999; Syrett and Silva, 1999; Silva, 2001 (forthcoming)). The decision by central government to create RDAs via a bottom-up process illustrates the increasingly dense set of relations between public and private sectors at the sub-national scale which have emerged in recent years, and how these now provide a potential basis for the decentralization of certain regional development activities.

The legal definition concerning the type of activities which RDAs can engage in provides considerable scope for developing pro-active regional initiatives within the parameters of national state policy. As independent and self-sustaining bodies functioning on a partnership basis, the RDAs have a clear basis for becoming significant regional actors through the definition and implementation of regional programmes. However, Portuguese RDAs must carve out this role for themselves, rather than merely taking on a prescribed and guaranteed role. Their ability to do this will emerge out of the interaction of the varying capacities of the individual RDAs and the fundamental limitations placed upon the activities of all RDAs by their limited financial and political power.

The formation process has led to a set of agencies with uneven spatial coverage, exhibiting considerable variation in terms of size, composition and experience. The result is that some RDAs are much better equipped to become successful regional institutions than others. The best developed are rooted within strong pre-existing partnerships and where there is a strong sense of regional identity and common objectives. The strong degree of variability suggests that some degree of rationalization will be required to ensure that the RDAs are of a sufficient size to carry out a strategic regional role. This is particularly the case in the north and the centre of the country which is covered by 11 different agencies. However, any rationalization will be faced with the very factors which led to the creation of the initial RDAs (i.e. sense of identity, existing co-operative relations, etc.) thus making compromise solutions difficult to achieve. The inverse of this problem, the lack of co-operation within certain regions (e.g. the Lisbon Metropolitan Area), is likely to make it difficult for future RDAs to emerge in areas not currently covered by an agency.

As currently constituted, the RDAs are too small and their resources too limited for them to develop a strong strategic regional role. Over time it may be possible for some RDAs to develop this type of role in partnership with other regional actors. In order to achieve this they will need to overcome key constraints related to their level of funding and their degree of legitimacy derived from the nature of their role within the governance system.

Funding. The RDAs have been set up to be selfsustaining without any guaranteed provision of direct public sector funding streams. Whilst this is a major advantage in providing complete financial independence from the state administration, it is also the source of a major constraint - a lack of core funding. Currently, for the RDAs, other than any core funding that they have been able to negotiate from their partners, they are reliant on generating income from the supply of services. Consequently there is a clear danger here of the RDAs becoming little more than small, regional consultancy organizations where the need to generate income takes precedence over broader aims of developing and implementing a regional economic strategy.

The current capacity of the RDAs to generate income and become self-sustaining is highly variable. If it is accepted that the aim for self-sustaining RDAs is desirable and necessary, there remains a strong case for some further short term central state funding, perhaps under an IQADE-II, in order to support the less well developed RD As towards achieving this goal. There remains a need to recruit further staff and improve staff skills and management structures given that most have been set up with limited finance and have been in operation for only one year. If further resources are not made available to consolidate what has been achieved so far, there is a distinct possibility that certain RDAs will fail and the investments made to date will be lost.

During this difficult start-up period the RD As have suffered from the hiatus between the end of the Second Community Support Framework (CSF-II) and the start of transfers under the Third Community Support Framework (CSF-III). More positively, the commencement of CSF-III in late 2000 means that the 
RDAs are well placed to apply for considerable EU funding for regional initiatives (MINISTÉRIO DE Planeamento, 2000b). However, in the longer term, given a major reduction in incoming $\mathrm{EU}$ funds to Portugal is likely after 2006, the RD As must be wary of becoming over reliant on these funding sources. There does exist considerable scope for the strengthening of relations with the CCRs, which could pass responsibility for the execution of parts of the regional programmes to the RDAs. Such working relationships could also extend to other areas of central government activity, but for the moment the RDAs must rely on generating their own finance and strengthening the financial relationships with their regionally based partners.

Legitimacy and inter-institutional relationships. Despite the limitations imposed by lack of funding, the greatest advantage the RDAs have is a degree of regionally based legitimacy. Whilst this is not electorally derived, their independence from the state and their bottomup genesis are positive attributes which favour the development of working relations with other local and regional partners. Combined with wide ranging roots in institutions from civil society, public and private sectors, they also possess a degree of flexibility in operation as non-public entities which state institutions in Portugal traditionally lack. Given the strong tradition of state clientelism within Portugal, the RDAs are unanimous in their view that they must retain this autonomy if they are to prosper. Yet recognition that the central state remains the key source of power for most regionally based activity ensures the need to develop working relationships with the central administration. The challenge will be for the RD As to develop strong relations with central government yet remain outside the fluctuations of political power resulting from governmental and ministerial changes, which continue to adversely affect many agencies within Portugal.

The basis of this view is reinforced by the recent history of the RDAs. In comparison to the previous PS government (1995-99), the current PS government's commitment to the RDAs appears more muted. ${ }^{6}$ This situation has hampered the development of the RDAs during the important start-up period. The extent to which current and future governments see the RDAs as an essential platform for regional economic development, and a potential vehicle for greater devolution of regional development activities to elements of civil society, will clearly be important for their future development. As currently constituted, the co-ordination of national sectoral policies at the regional scale remains beyond the powers of the RD As and it appears unlikely that this situation is likely to change in the near future. The need to lobby central government with a unified voice to ensure that the RDA role is promoted effec- tively has already been recognized, resulting in the creation of a national association for the RDAs.

The lack of devolved power and the lukewarm promotion of the RDAs by the central state reinforces the importance of relationships with other sub-regional state entities promoting economic development. Associations of local authorities are key partners within virtually all RDAs, further marking the trend towards greater intermunicipal co-operation. However, municipal rivalry and competition remains. RD As need to convince municipalities of the advantages of greater cooperation across a range of economic development activities. The relationship with the CCRs, who remain the major regional level actors, is critical. Interestingly, in a small number of cases CCRs are partners within the RDAs, whilst in the majority they are not. As was observed with respect to finance, close working relationships with the CCRs could provide considerable opportunities for developing their strategic role. Conversely, conflictual relations could be highly damaging.

In their relationships with these state bodies and the diverse range of other local and regional institutions, RD As need to strengthen their regionally based profile. To date, outside of their immediate partners, there is little knowledge and understanding of what RDAs are, and what they are seeking to achieve. Furthermore, even within the participating partners there are often strongly diverging interests with regard to future regional development strategies. In order to gain regional credibility and recognition, RDAs need to demonstrate their utility especially through involvement in successful initiatives. Ultimately the ability of the RDA to lead diverse interests towards the creation of an overall regional strategy will be based on their legitimacy with a range of local and regional partners, and in the absence of this, they will be destined to remain politically marginalized.

The risks of this situation are clearly evident with respect to previous experiences of development agencies within Portugal. In Lisbon, the agency AMBELIS, which is not one of the new RDAs, was created in 1994 to spearhead the implementation of the Lisbon Strategic Plan (Syrett and Silva, 1999). However, it has failed to develop a strategic leadership role due to its limited scale, reduced area of operation and its lack of power in relation to a wide range of diverse and often divergent interests. As a result, AMBELIS has remained politically isolated and lacks credibility as a strategic, city-wide agency. Rather than contributing to improved metropolitan governance, AMBELIS has instead further contributed towards the excessive fragmentation, duplication and institutional complexity which currently characterizes the Lisbon metropolitan area.

\section{Conclusions}

The process of creating RDAs in Portugal illustrates how particular national political contexts and existing 
institutional structures shape the types and styles of development agencies. In the Portuguese case, in a country notable for the dominance of the central state administration, there has been a deliberate effort to create RDAs which have financial and political independence and strong regional roots. The RDAs are an attempt to move towards new governance systems by creating a new institutional form: one that is embedded within partnership working, more entrepreneurial by nature and not heavily dependent on public sector resources. There is considerable merit in attempting to create more flexible, regionally sensitive and market oriented institutions to promote economic development within Portugal given the current lack of such forms. However, the difficulty is that, as the RD As lie outside of the powerful state administration, there is the danger that they are consigned to operate only on the margins, lacking the financial and political power to make any significant impact.

The ability of the RDAs to respond positively to these constraints will to a large extent determine whether they become a major instrument for the modernization of regional development policy in Portugal, or just another institution overlain on an already dense and complex institutional fabric. It is as yet too early for the RDAs to demonstrate their capabilities given they are encountering a number of start-up problems resulting from their innovatory character. In the short term the RDAs appear set to continue to operate, with varying degrees of success, throughout the operation of Third Community Support Framework. A key test for their self-sustainability will be when this comes to an end in 2006/07 and the flow of EU funds is dramatically reduced. By this point, those with a sound financial base and regional role actively supported by their partners will be better positioned to develop an autonomous regional strategy. Ultimately, as more networked forms of governance develop in Portugal, it will be the ability of individual RDAs to promote regionally based partnerships and legitimate their own role within these, which will determine whether they successfully carve out the strategic regional level role originally envisaged for them.

\section{Notes}

1. The IQADE (Implementação e Qualificação de Agências de Desenvolvimento) programme formed part of the wider national programme for promoting regional development potential (PPDR - Programa de Promoção do Potencial do Desenvolvimento Regional) one of the components of the Second Community Support Framework for Portugal. The analysis is based on a series of interviews with RDA directors and technical staff and with the Chief Executive of IQADE-II (see also SILVA and Syrett, 2000).

2. A number of the proposed RDAs failed to meet the population threshold of 300,000 and this criterion was subsequently abandoned.
3. The legislative basis for RDAs is contained in DecretoLei, no. 88/99 of 19 March 1999. In order to receive state support RDAs needed to conform to a series of legal requirements (Portaria 282/99, de 26/4) which were verified by the DGDR (Regional Development Directorate). Only institutions created and registered within the contexts of the programme were able to be designated RD As. Consequently, the several pre-existing development agencies had to decide whether to apply to become official RDAs, or continue working but without the RDA designation.

4. The only bodies legally prevented from participating in RDAs are entities which promote party political activity.

5. Information on RDA staff was provided by 15 of the 17 RDAs contacted.

6. In the late 1990s it was possible that the RDAs could have been given a much more powerful role as an alternative way of decentralizing state activity in the light of the rejection of the regionalization proposals. For example, the Ministry of Planning and Internal Affairs (MEPAT) proposed at the start of 1999 that a substantial part of EU Structural Funds should be managed at the regional level, thus potentially creating for the RDAs a key part within this process. Furthermore, at this time the regulators of the Structural Funds were putting a strong emphasis on this form of inter-institutional solution not only in the definition of policy, but also with respect to implementation under the Third Community Support Framework (2000-06). However, as a result of interdepartmental power struggles a more high profile role for the RDAs did not materialize.

\section{References}

Corkill D. (1999) Portugal's 1998 referendums, West European Politics 22, 186-92.

Direç̧ão-Geral da Administração Local (DGAL) (1999) Finanças Locais: Aplicação em 1999, Indicadores Municipais 18, DGAL, Lisbon.

Imprensa NaCional Casa da Moeda (INCM) (1999) GOP: Grandes Opções do Plano, 1999. INCM, Lisbon.

IQADE (1997) Sinopse dos Projectos de Agências de Desenvolvimento Regional. IQADE, Lisbon.

Jessop B. (1994) Post-Fordism and the state, in Amin A. (Ed) Post-Fordism: A Reader, pp. 251-79. Blackwell, Oxford.

Kearns A. and Paddison R. (2000) New challenges for urban governance, Urban Studies 37, 845-50.

Lloyd P. and Meegan R. (1996) Contested governance: European exposure in the English regions, Europ. Plann. Studies 4, 75-97.

Ministério do Equipamento, Planeamento E Administração do Território (MEPAT) (1999) PNDES: Plano Nacional de Desenvolvimento Económico e Social, 2000-2006. MEPAT, Lisbon.

Ministério do Planeamento (2000a) Plano de Desenvolvimento Regional, Portugal 2000-2006. Ministério do Planeamento, Lisbon.

Ministério do Planeamento (2000b) Quadro Comunitário de Apoio III, Portugal 2000-2006. Ministério do Planeamento, Lisbon.

Moreira V. (1999) Começar de novo, pela base, Público, 27 July. 
Newman P. (2000) Changing patterns of regional governance in the EU, Urban Studies 37, 895-908.

Promoção do Potencial de Desenvolvimento Regional (PPDR) (1998) IQADE - Projecto de Implementação e Qualificação de Agências de Desenvolvimento em Portugal. PPDR, Lisbon.

Promoção do Potencial de Desenvolvimento Regional (PPDR) (2000) IQADE-II Projecto de Qualificação Estrutural e Técnica de Agências de Desenvolvimento. PPDR, Lisbon.

Silva C. N. (2001, forthcoming) Local and regional government in contemporary Portugal: continuity and innovation in local governance, in SyRETT S. (Ed) Contemporary Portugal: Dimensions of Economic and Political Change. Ashgate, Aldershot.
Silva C. N. and Syrett S. (2000) Agências de Desenvolvimento Regional em Portugal: que futuro?, Cadernos Municipais 14(72), 36-47.

SyRETT S. (1997) The politics of partnership: the role of social partners in local economic development, Europ. Urban \& Reg. Studies 4, 99-114.

Syrett S. and Silva C. N. (1999) New institutions for new forms of governance: Regional Development Agencies in Portugal, paper presented at Regional Studies Association International Conference, Bilbão, September.

Tewdwr-Jones M. and McNeill D. (2000) The politics of city-region planning and governance, Europ. Urban \& Reg. Studies 7, 119-34. 